www.jmscr.igmpublication.org

Impact Factor 3.79

Index Copernicus Value: 5.88

ISSN (e)-2347-176x ISSN (p) 2455-0450

crossref DOI:_http://dx.doi.org/10.18535/jmscr/v3i12.04

\title{
A Review Case of Laparoscopic Management of Adrenal Myelolipoma
}

Authors

\section{Dr Jitendra T. Sankpal ${ }^{1}$, Dr Mohammed Siddique J. A. ${ }^{2}$, Dr Mayank B. Mishra ${ }^{3}$}

${ }^{1}$ M.S. General Surgery, Associate Prof. and Unit Head, Dept. of Surgery, Grant's Government Medical College And J J Group of Hospital, Mumbai, Maharashtra

Email: drjts_palmbeach@yahoo.co.in

${ }^{2}$ DNB, General Surgery, FMAS, Assistant Prof. Dept. of Surgery, Grant's Government Medical College and JJ Group of Hospital, Mumbai, Maharashtra

Email: hashmisiddique2@gmail.com

${ }^{3}$ MS General Surgery, Senior Resident, Dept. of Surgery, Grant's Government Medical College And J J

Group of Hospital, Mumbai, Maharashtra

Email:drmayankb@gmail.com

\section{ABSTRACT}

Adrenal Myelolipoma is a rare benign neoplasm composed of mature adipose tissue and a variable amount of haemopoietic elements. Most lesions are small and asymptomatic, discovered incidentally during autopsy or on imaging studies performed for other reasons. A case of adrenal myelolipoma is presented here, where the tumour was hormonally inactive was managed by laparoscopic adrenalectomy.

KEYWORDS: Adrenal gland, Myelolipoma, Laparoscopic adrenalectomy.

\section{INTRODUCTION}

Myelolipomas were initially described by Giercke in 1905, and 24 years later, Oberling coined the term 'myelolipoma'. These are rare, benign tumours, usually found in the adrenal gland, although myelolipomatous foci can be present in other extra-adrenal locations. They are composed of mature adipocytes and normal haematopoietic tissues. They contain precursors of white and red blood cells such as megakaryocytes ${ }^{1}$.

The incidence of adrenal myelolipoma is reported as being 0.08 to $0.4 \%$ at autopsy ${ }^{2}$. Although the male-to-female ratio is $1: 1$, a study reported a male-to-female ratio of $2: 3^{3}$. With the vast use of non-invasive imaging, its incidental detection has become more common, reaching up to $7 \%$ of the adrenal masses ${ }^{4}$.Great numbers of incidentally discovered lesions are small and asymptomatic, but frequent cases of large symptomatic lesions have been reported. The well-recognised complication of adrenal myelolipoma is spontaneous retroperitoneal haemorrhage $e^{5,6}$. No potential of malignancy for adrenal myelolipoma has been proved. With the advent of minimal invasive surgery, laparoscopic adrenalectomy has shown a considerable decrease in surgically derived morbidity as well as hospital stay ${ }^{7}$.We report a case of asymptomatic myelolipoma where diagnosis was made on the basis of radiological investigations and was treated with laparoscopic adrenalectomy. 


\section{CASE HISTORY}

32 year old female came to hospital with history of infertility since 15 years for which undergone radiological investigations and diagnosed as right adrenal mass. Bowel and bladder habits were normal. Menstrual cycles were normal. General and systemic examinations were normal.

On ultrasound examination of abdomen: increased echogenic mass seen over upper pole of right kidney measuring $4 \times 3 \mathrm{~cm}^{2}$. CT scan of abdomen and pelvis showed enlarged right adrenal gland of size $6 \times 3.9 \mathrm{~cm}^{2}$.

Laboratory investigations revealed the normally functioning adrenal glands. Plasma cortisol level was $8.67 \mathrm{mcg} / \mathrm{dl}$. Plasma levels of free matanephrine and nor metanephrines were 19.9 $\mathrm{pg} / \mathrm{ml}$ and $29.7 \mathrm{pg} / \mathrm{ml}$ which were within normal limits.Diagnosis was confirmed on CT scan and the patient underwent laparoscopic right adrenalectomy with a smooth, postoperative recovery. Histopathology revealed myelolipoma.

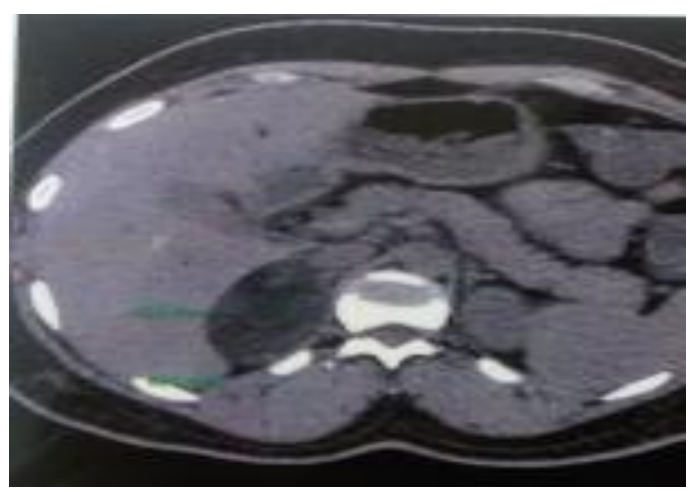

Figure 1 CT scan showing right adrenal mass

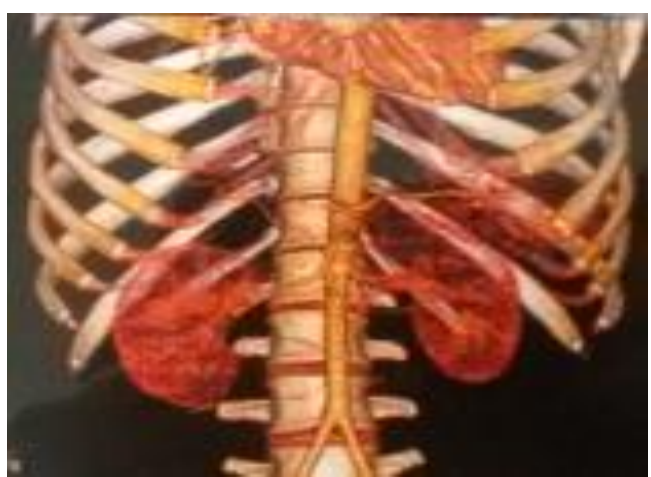

Figure 2 CT Scan with 3D reconstruction showing decreased vascularity of right adrenal gland

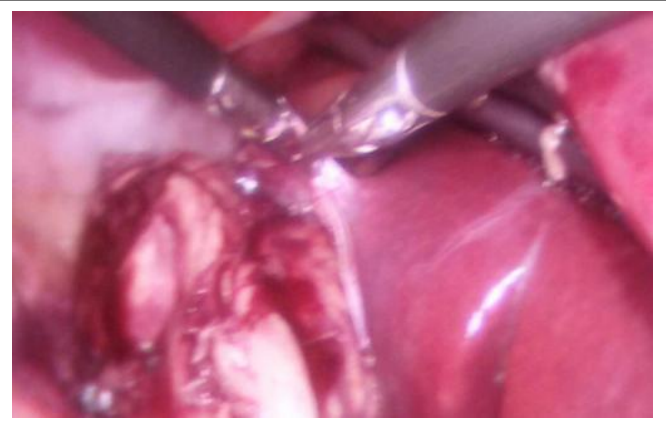

Figure 3 Laparoscopic view of right adrenal mass

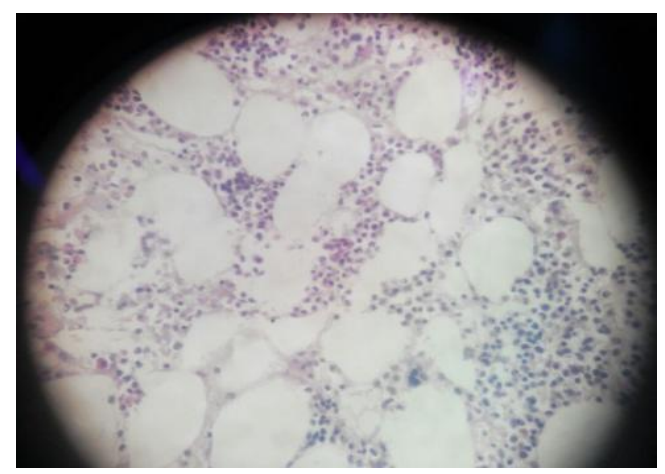

Figure 4 Histopathological examination showed mature fat cells with haemopoitic cells

\section{DISCUSSION}

Myelolipomas are small, non-functional and usually asymptomatic in nature. They are benign in nature. Nevertheless, it remains unclear how this tumour actually develops. The pathogenesis of myelolipomas remains speculative. Most widely accepted theory is the existence of metaplasia of reticuloendothelial cells of blood capillaries in the adrenal glands, in response to stimuli, such as, necrosis, infection or stress ${ }^{5}$.

Myelolipomas in our patient wasnot found with other medical conditions, such as, hypertension, diabetes mellitus and obesity. There is no proven link between these conditions and myelolipomas, yet elderly patients undergo imaging studies for other reasons, facilitating incidental diagnosis. As in our case, the patient has undergone imaging investigations for infertility and diagnosed as adrenal mass. Occasionally there are clinical symptoms such as abdominal pain or flank pain. Spontaneous retroperitoneal haemorrhage in association with myelolipoma has been described $^{6}$.

Histological examination of a myelolipoma shows adipocytes with interspersed haematopoietic 
elements, consisting of myeloid and erthyroid precursors, as well as, megakaryocytes ${ }^{6}$. When a suspicious mass is symptomatic or when diagnosis is not clear, surgical exploration becomes necessary. Traditionally the classic approach to this pathology has been open surgery ${ }^{6}$. Ever since its introduction by Gagner in 1992, laparoscopic adrenalectomy has become the standard of care for the treatment of functioning and nonfunctioning adrenal tumours. Many authors have found a decrease in perioperative morbidity and convalescence after this procedure when compared with open surgery ${ }^{7}$.

We conclude that adrenal myelolipomas are rare tumours. Patients with small, asymptomatic myelolipomas must be monitored clinically for symptoms and routine follow-up imaging studies appear unnecessary for such lesions. Surgical treatment must be reserved for selected patients with large and symptomatic lesions. Occasionally large silent tumours are excised, to prevent the occurrence of a rupture or intra-tumoural haemorrhage.

\section{REFERENCES}

1. Kenney PJ et al. Myelolipoma: CT and pathologic features. Radiology. 1998; 208:87-95.

2. Olsson CA et al. Adrenal myelolipoma. Surgery.1973;73:665-70.

3. Han $\mathbf{M}$ et al. The natural history and treatment of adrenal myelolipoma. J Urol. 1997;157:12-16.

4. Aso Y, Homma Y. A survey on incidental adrenal tumours in Japan. J Urol.1992; 147:1478-81.

5. Meaglia JP, Schmidt JD. Natural history of an adrenal myelolipoma. J Urol.1992; 147:1089-90.

6. Lawler LP, Pickhardt PJ. Giant adrenal myelolipoma presenting with spontaneoushemorrhage: CT, MR and pathology correlation. Ir Med J. 2001; 94:231.
7. Novitsky YW et al. Feasibility of laparoscopic adrenalectomy for large adrenal masses. Surg Laparosc Endosc Percutan Tech. 2003;13:106-10. 